\title{
Prevalence of lumbar spondylosis and its association with low back pain among community-dwelling Japanese women
}

\author{
Ritsu Tsujimoto', Yasuyo Abe ${ }^{2}$, Kazuhiko Arima² ${ }^{2}$ (D, Takayuki Nishimura², Masato Tomita', Akihiko Yonekura', \\ Takashi Miyamoto ${ }^{1}$, Shohei Matsubayashi ${ }^{1}$, Natsumi Tanaka², Kiyoshi Aoyagi ${ }^{2}$ and Makoto Osaki ${ }^{1}$
}

\begin{abstract}
Background: Lumbar spondylosis is more prevalent among the middle-aged and elderly, but few populationbased studies have been conducted, especially in Japan. The purpose of this study was to explore the prevalence of lumbar spondylosis and its associations with low back pain among community-dwelling Japanese women.

Methods: Lateral radiographs of the lumbar spine were obtained from 490 Japanese women $\geq 40$ years old, and scored for lumbar spondylosis using the Kellgren-Lawrence $(K L)$ grade at lumbar intervertebral level from $L 1 / 2$ to L5/S1. Height and weight were measured, and body mass index (BMI) was calculated. Low back pain in subjects was assessed using a self-administered questionnaire. Stiffness index (bone mass) was measured at the calcaneal bone using quantitative ultrasound.

Results: Prevalence of radiographic lumbar spondylosis for $\mathrm{KL} \geq 2, \mathrm{KL} \geq 3$ and low back pain were $76.7 \%$, 38.8\% and $20.0 \%$, respectively. Age was positively associated with radiographic lumbar spondylosis $(K L=2, K L \geq 3$ ) and low back pain. Greater BMI was associated with lumbar spondylosis with $K L=2$, but not with $K L \geq 3$. Stiffness index was associated with neither radiographic lumbar spondylosis nor low back pain. Multiple logistic regression analysis identified radiographic lumbar spondylosis $(K L \geq 3)$ at $L 3 / 4, L 4 / 5$ and $L 5 / S 1$ was associated with low back pain, independent of age, BMI and stiffness index.
\end{abstract}

Conclusion: Severe lumbar spondylosis at the middle or lower level may contribute to low back pain.

Keywords: Lumbar spondylosis, Epidemiology, Community-based study, Low back pain

\section{Background}

Lumbar spondylosis is characterized by disc degeneration and osteophytosis, and is more prevalent among the middle-aged and elderly [1-9]. Since lumbar spondylosis causes low back pain $[1,3,7,9-11]$, it is important to clarify the prevalence, elucidate associated factors, and identify methods to prevent the disease. Although this disorder has been widely studied in clinical settings, few population-based studies have been conducted, especially in Japan [1-20].

Previous studies have shown that the prevalence of lumbar spondylosis ranges from $38 \%$ to $85 \%[1-7,9,10,12-16]$.

\footnotetext{
*Correspondence: kzarima-ngs@umin.ac.jp

${ }^{2}$ Department of Public Health, Nagasaki University Graduate School of Biomedical Sciences, 1-12-4 Sakamoto, Nagasaki 852-8523, Japan Full list of author information is available at the end of the article
}

Yoshimura et al. reported that severe lumbar degenerative disease is more common in the United Kingdom than in Japan, possibly due to ethnic differences [13]. Previous studies have shown that lumbar spondylosis is associated with age $[1-10,12,16]$, obesity $[3,4,7,14]$ and bone mass [20-22]. On the other hand, some studies have found no association with obesity $[5,10]$. Mericonda et al. [18] found a significant positive correlation between ultrasonographic parameters at the calcaneal bone and scores on a degenerative scale that primarily reflect intervertebral disc degeneration only in men, suggesting that associations may differ between sexes. Several studies have found an association between lumbar spondylosis and low back pain $[1,3,7,9,10]$, but others have not $[15,16,19]$. Whether lumbar spondylosis causes low back pain remains controversial. 
The prevalence of lumbar spondylosis and associations with low back pain have yet to be fully elucidated. The purpose of this study was to explore the prevalence of lumbar spondylosis and its associations with low back pain among community-dwelling Japanese women.

\section{Methods}

\section{Study design and participants}

This study was conducted as part of a survey of age-related health status in a Japanese community (the Oshima Health Study). All women $\geq 40$ years old in Oshima, a town in Nagasaki Prefecture in Japan, were invited to participate. Oshima has a population of approximately 5,800 (2,850 men, 2,950 women), including approximately 2,000 women $\geq 40$ years. Despite having a shipyard in the town, Oshima is primarily a rural area. The examination of each subject was performed at the Oshima Health Center between 2001 and 2003. A total of 573 women (approximately $30 \%$ of eligible women) participated in the study. All participants were non-institutionalized, lived independently, and provided written informed consent before examinations. All study protocols were approved by the Ohshima local ethics committee.

\section{Measurements}

Height (in meters) and weight (in kilograms) were measured with the subject in light clothing and without shoes, and body mass index (BMI) was calculated as weight/height ${ }^{2}$. Subjects were asked if they had low back pain on most days during the previous one month using a self-administered questionnaire (yes/no). Information on current smoking and alcohol drinking was also obtained (yes/no). Stiffness index (bone mass) was also measured at the calcaneal bone using quantitative ultrasound (QUS). Broadband ultrasound attenuation (BUA: $\mathrm{dB} / \mathrm{MHz}$ ) and the speed of sound (SOS: $\mathrm{m} / \mathrm{s}$ ) were measured with an Achilles ultrasound bone densitometer (GE Lunar, Madison, WI). Stiffness index, a function of BUA and SOS, was automatically calculated by using the scanner software [23].

\section{Spine radiographic assessment}

Lateral radiographs of the lumbar spine were obtained with the subject lying on their side with knees bent. Radiographs were scored by a single experienced orthopedic surgeon (RT) for lumbar spondylosis using the Kellgren-Lawrence (KL) grade as follows: KL0, normal; KL1, slight osteophytes; KL2, definite osteophytes; KL3, disc space narrowing with osteophytes; KL4, bone sclerosis, disc space narrowing, and large osteophytes [24] (Fig. 1). The present study defined a spine with disc space narrowing with or without osteophytes as KL3. KL grade was determined at the intervertebral level from L1/2 to L5/S1. To evaluate the Intra- observer variability of $\mathrm{KL}$ grading, randomly selected radiographs of the lumbar spine were scored by the same reader more than 1 month after the first reading for 50 individuals. Furthermore, 50 other radiographs were scored by two experienced orthopedic surgeons (RT and SM) using the same radiographic atlas for inter-observer variability. Intra- and inter-observer variability was then evaluated by kappa analysis. The radiographic readers (RT and SM) were blind to subject age and other characteristics.

\section{Statistical analysis}

Seventy-seven women for whom radiographs showed poor technical quality and seven women with missing data on low back pain were excluded, leaving 490 women for analysis. The Cochran-Armitage trend test was used to evaluate differences in the prevalence of radiographic lumbar spondylosis or low back pain among age groups. Age-specific means of stiffness index were determined using a general linear modelling method. Logistic regression analysis was used to explore the associations of age, BMI and stiffness index with radiographic lumbar spondylosis (based on the worst level of spondylosis) or low back pain, and the associations of KL grade at each intervertebral level with low back pain, adjusting for age, BMI and stiffness index. Furthermore, we assigned scores as follows: $0, \mathrm{KL}=0-1$; $1, K L=2$; and $2, K L \geq 3$. Scores for each level were totaled for each individual (range, 0-10). We conducted logistic regression analysis in order to examine the association between total score for spondylosis at each level and low back pain, adjusting for age, BMI and stiffness index. Results are presented as odds ratios (ORs) with 95\% confidence intervals (CIs). Data were analyzed using Statistical Analysis System software package version 9.2 (SAS Institute, Cary, NC).

\section{Results}

Intra- and inter-observer variability in the KL grading of lumbar radiographs were found to be sufficient, with "substantial" kappa scores of 0.78 (95\%CI: 0.62-0.94) and 0.63 (95\%CI: 0.44-0.83), respectively.

Characteristics of subjects are presented in Table 1. Mean (standard deviation) age, BMI and stiffness index were $64.3(10.7)$ years, $23.3(3.3) \mathrm{kg} / \mathrm{m}^{2}$, and $68.8(16.1)$, respectively.

Overall prevalence of radiographic lumbar spondylosis for $\mathrm{KL} \geq 2, \mathrm{KL} \geq 3$ and low back pain were $76.7 \%$, 38.8\% and $20.0 \%$, respectively (Table 2 ). The prevalence of radiographic lumbar spondylosis of $\mathrm{KL} \geq 2(p<0.001), \mathrm{KL} \geq 3$ $(p<0.001)$ and low back pain $(p=0.006)$ increased with age. Stiffness index decreased with age $(p<0.001)$. Numbers (\%) of subjects with radiographic lumbar spondylosis at each intervertebral level are shown in Table 3. Higher prevalence of radiographic lumbar spondylosis $(K L \geq 2)$ 


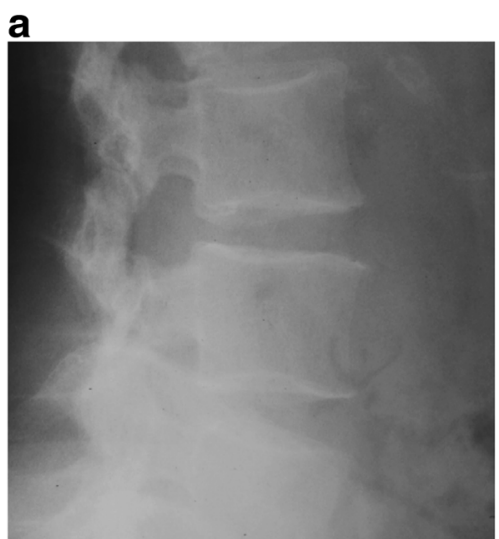

b

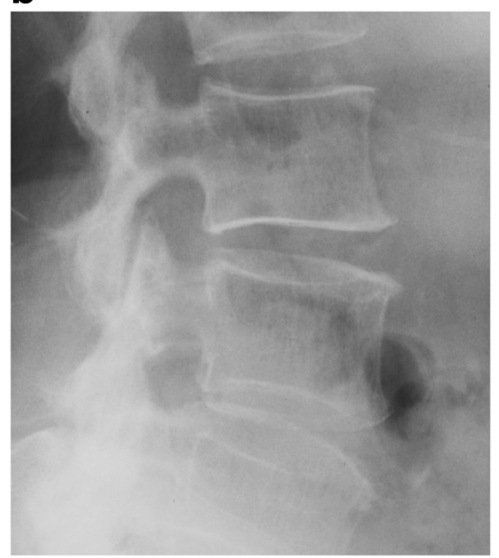

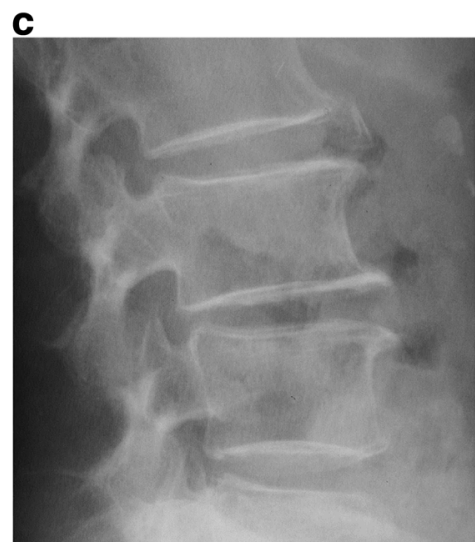

d

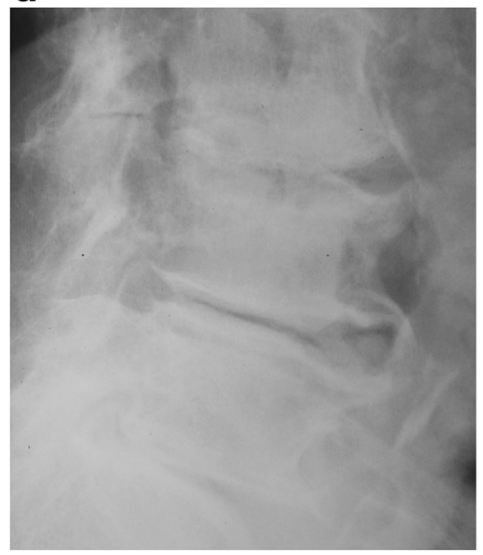

Fig. 1 Radiographs were scored for lumbar spondylosis using the Kellgren-Lawrence (KL) grade as follows: KL1, slight osteophytes (a); KL2, definite osteophytes (b); KL3, disc space narrowing with osteophytes (c); KL4, bone sclerosis, disc space narrowing, and large osteophytes (d)

was seen at L3/4 (50.8\%) and L2/3 (48.4\%). Higher prevalence of radiographic lumbar spondylosis $(\mathrm{KL} \geq 3)$ was seen at L5/S1 (17.1\%) and L4/5 (14.5\%).

Age was positively associated with radiographic lumbar spondylosis $(K L=2, K L \geq 3$; with worst level selected) and low back pain (Table 4). The OR with a 10year increase in age was 2.37 in $\mathrm{KL}=2,2.37$ in $\mathrm{KL} \geq 3$ and 1.34 in low back pain. Greater BMI was associated with lumbar spondylosis with $K L=2$, but not with $K L \geq$ 3. The OR with a 1-SD $\left(3.3-\mathrm{kg} / \mathrm{m}^{2}\right)$ increase in BMI was

Table 1 Subject characteristics

\begin{tabular}{ll}
\hline No. of subjects & 490 \\
Age (years) & $64.3 \pm 10.7$ \\
Height $(\mathrm{cm})$ & $150.1 \pm 6.53$ \\
Weight $(\mathrm{kg})$ & $52.4 \pm 8.51$ \\
$\mathrm{BMI}\left(\mathrm{kg} / \mathrm{m}^{2}\right)$ & $23.3 \pm 3.3$ \\
Stiffness index & $68.8 \pm 16.1$ \\
Current smoker (\%) & 4.1 \\
Current drinker (\%) & 8.8 \\
\hline
\end{tabular}

Data are given as mean \pm SD $B M I$ body mass index
1.59 in $\mathrm{KL}=2$. BMI was not associated with $\mathrm{KL}=3$, relative to $K L=0-2$ (data not shown). Stiffness index was associated with neither radiographic lumbar spondylosis nor low back pain.

Through multiple logistic regression analysis, Table 5 shows the association of $K L$ grade $(K L=2$ and $K L \geq 3)$ at each intervertebral level with low back pain relative to KL 0 or 1, adjusting for age, BMI and stiffness index. Radiographic lumbar spondylosis $(\mathrm{KL} \geq 3)$ at $\mathrm{L} 3 / 4, \mathrm{~L} 4 / 5$ or L5/S1 was associated with low back pain, independent of other covariates. We repeated the analysis for the association of $K L \geq 2$ with low back pain relative to $K L$ $<2$, and of $K L \geq 3$ relative to $K L<3$. Similar results were obtained; lumbar spondylosis $(\mathrm{KL} \geq 3)$ at $\mathrm{L} 3 / 4, \mathrm{~L} 4 /$ 5 or L5/S1 was associated with low back pain, but lumbar spondylosis $(K L \geq 2)$ at each level was not, except L5/S1. We conducted logistic regression analysis in order to examine the association between total spondylosis score at each level and low back pain, adjusting for age, BMI and stiffness index. A 1-point increase in spondylosis score was significantly associated with an increased risk of low back pain (OR: 1.2, 95\%CI: 1.1-1.3) (data not shown). 
Table 2 Number (\%) of subjects with radiographic lumbar spondylosis and low back pain and mean of stiffness index according to age

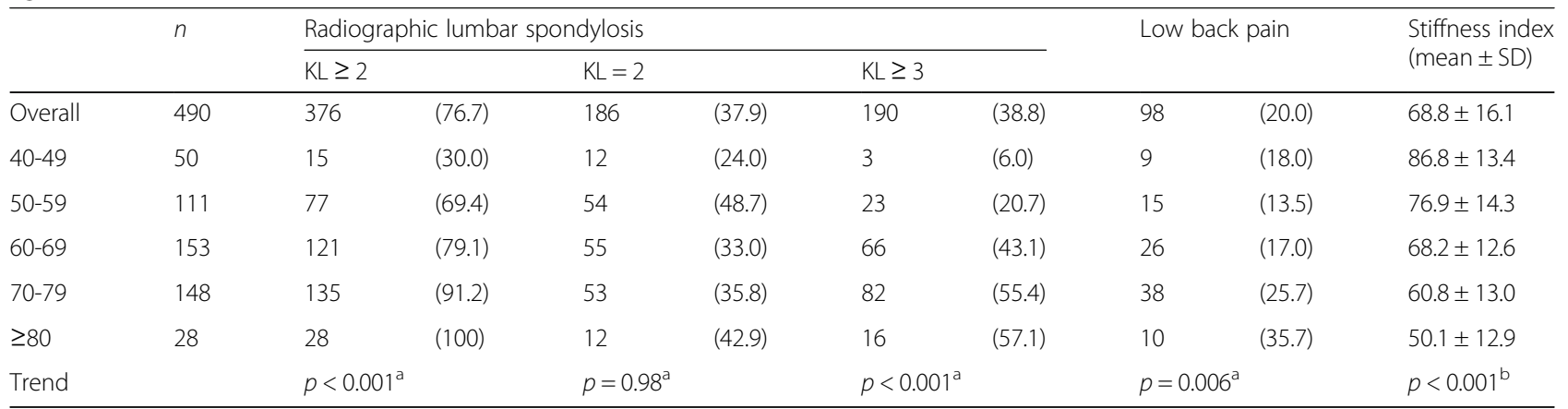

$n$ number, $K L$ Kellgren-Lawrence grading; Stiffness index, stiffness index by quantitative ultrasound at calcaneal bone

${ }^{a}$ Cochran-Armitage test

beneral linear modelling method

\section{Discussion}

We showed that the overall prevalence of radiographic lumbar spondylosis of $\mathrm{KL} \geq 2$ or $\mathrm{KL} \geq 3$ and low back pain was $76.7 \%, 38.8 \%$ and $20.0 \%$, respectively, among community-dwelling Japanese women $\geq 40$ years old. Previous studies have reported the prevalence as between 38 and $85 \%[1-7,9,10,12-16]$. These differences may be due to age distribution, sex, ethnicity and definition of lumbar spondylosis. Yoshimura et al. [13] reported a difference in the prevalence of lumbar spondylosis between the United Kingdom and Japan.

Muraki et al. [7] showed that in women $\geq 60$ years, the prevalence of radiographic lumbar spondylosis with $K L \geq 2, K L \geq 3$ and low back pain were $70.7 \%$, $52.1 \%$ and $31.2 \%$, respectively, in a large-scale population study in Japan. Those results were slightly higher than our own. When we selected women $\geq 60$ years old as subjects, prevalence of radiographic spondylosis

Table 3 Number and percentage of subjects with radiographic lumbar spondylosis at each intervertebral level

\begin{tabular}{lllllll}
\hline & $\begin{array}{l}\text { Overall } \\
(n=490)\end{array}$ & $\begin{array}{l}40-49 \\
(n=50)\end{array}$ & $\begin{array}{l}50-59 \\
(n=111)\end{array}$ & $\begin{array}{l}60-69 \\
(n=153)\end{array}$ & $\begin{array}{l}70-79 \\
(n=148)\end{array}$ & $\begin{array}{l}\geq 80 \\
(n=28)\end{array}$ \\
\hline $\mathrm{KL} \geq 2$ & & & & & \\
$\mathrm{~L} 1 / 2$ & $163(33.3)$ & $4(8.0)$ & $17(15.3)$ & $48(31.3)$ & $73(52.7)$ & $21(75.0)$ \\
$\mathrm{L} 2 / 3$ & $237(48.4)$ & $6(12.0)$ & $47(42.3)$ & $75(49.0)$ & $88(59.5)$ & $21(75.0)$ \\
$\mathrm{L} 3 / 4$ & $249(50.8)$ & $10(20.0)$ & $50(45.0)$ & $82(53.6)$ & $86(58.1)$ & $21(75.0)$ \\
$\mathrm{L} 4 / 5$ & $200(40.8)$ & $7(14.0)$ & $31(27.9)$ & $72(47.1)$ & $76(51.4)$ & $14(50.0)$ \\
$\mathrm{L} 5 / \mathrm{S} 1$ & $157(32.0)$ & $4(8.0)$ & $21(18.9)$ & $37(24.1)$ & $70(47.2)$ & $15(53.6)$ \\
& $\mathrm{KL} \geq 3$ & & & & & \\
$\mathrm{~L} 1 / 2$ & $48(9.8)$ & $1(2.0)$ & $3(2.7)$ & $12(7.8)$ & $25(16.9)$ & $7(25.0)$ \\
$\mathrm{L} 2 / 3$ & $47(9.6)$ & $0(0)$ & $3(2.7)$ & $15(9.8)$ & $27(18.2)$ & $2(7.1)$ \\
$\mathrm{L} 3 / 4$ & $39(8.0)$ & $1(2.0)$ & $2(1.8)$ & $11(7.2)$ & $19(12.8)$ & $6(21.4)$ \\
$\mathrm{L} 4 / 5$ & $71(14.5)$ & $0(0)$ & $7(6.3)$ & $28(18.3)$ & $29(19.6)$ & $7(25.0)$ \\
$\mathrm{L} 5 / \mathrm{S} 1$ & $84(17.1)$ & $2(4.0)$ & $13(11.7)$ & $28(18.3)$ & $36(24.3)$ & $5(17.9)$ \\
\hline
\end{tabular}

$n$ number, $K L$ Kellgren-Lawrence grading with $\mathrm{KL} \geq 2, \mathrm{KL} \geq 3$ and low back pain was $86.3 \%$ (284/329), 50.2\% (165/329) and $22.5 \%$ (74/329), respectively, similar to the results above.

Several studies have shown older age to be associated with lumbar spondylosis [1-10, 12, 16] We also showed that older age was associated with lumbar spondylosis of $\mathrm{KL}=2$ and $\mathrm{KL} \geq 3$.

In our study, greater BMI was associated with lumbar spondylosis with $K L=2$, but not with lumbar spondylosis with $\mathrm{KL} \geq 3$, which suggests that greater BMI may be associated with moderate lumbar spondylosis. Some studies have reported that obesity is related to lumbar spondylosis $[3,4,7,14]$, but others have not $[5,10]$. Yoshimura et al. [13] reported that obesity was related to lumbar spondylosis in the United Kingdom, but not in Japan. According to van Saase et al. [17], the relationship between obesity and lumbar spondylosis differed between sexes. Obesity was related to lumbar spondylosis with $\mathrm{KL} \geq 2$ in both sexes. On the other hand, obesity correlated negatively with lumbar spondylosis of $K L \geq 3$ only in women, not in men. The relationship between obesity and lumbar spondylosis may differ by severity, ethnicity or sex.

In our study, stiffness index from QUS was not associated with lumbar spondylosis. Mariconda et al. [18] studied whether QUS, a radiation-free, easy-to-operate, inexpensive and rapid technique, might prove useful in predicting the extent of degenerative changes in the lumbar spine, showing that stiffness index was positively associated with lumbar disc degeneration in men, but not in women. Furthermore, bone mineral density (BMD) by dual-energy X-ray absorptiometry (DEXA) was reported to be positively associated with lumbar spondylosis or disc degeneration [20-22]. Assessment of the association of BMD with lumbar spondylosis or disc degeneration must be made with caution because of differences in measurement methods (QUS or DEXA) and measurement sites (heel, lumbar or femoral neck). 
Table 4 Associations of age, BMI, and stiffness index with radiographic lumbar spondylosis and low back pain

\begin{tabular}{|c|c|c|c|c|}
\hline & \multirow{3}{*}{ Unit } & \multicolumn{2}{|c|}{ Radiographic lumbar spondylosis } & \multirow[t]{2}{*}{ Low back pain } \\
\hline & & $\mathrm{KL}=2$ & $\mathrm{KL} \geq 3$ & \\
\hline & & $\begin{array}{l}\text { OR } \\
(95 \% \mathrm{Cl})\end{array}$ & $\begin{array}{l}\text { OR } \\
(95 \% \mathrm{Cl})\end{array}$ & $\begin{array}{l}\text { OR } \\
(95 \% \text { Cl) }\end{array}$ \\
\hline Age (years) & 10-year increase & $\begin{array}{l}2.37 \\
(1.68-3.16) \dagger\end{array}$ & $\begin{array}{l}2.37 \\
(1.76-2.92) \dagger\end{array}$ & $\begin{array}{l}1.34 \\
(1.00-1.71)^{*}\end{array}$ \\
\hline BMI $\left(\mathrm{kg} / \mathrm{m}^{2}\right)$ & One SD (3.3) increase & $\begin{array}{l}1.59 \\
(1.17-2.11) *\end{array}$ & $\begin{array}{l}1.10 \\
(0.89-1.32)\end{array}$ & $\begin{array}{l}1.00 \\
(0.79-1.25)\end{array}$ \\
\hline Stiffness index & One SD (16.1) increase & $\begin{array}{l}1.17 \\
(0.81-1.51)\end{array}$ & $\begin{array}{l}1.00 \\
(0.72-1.19)\end{array}$ & $\begin{array}{l}0.85 \\
(0.65-1.17)\end{array}$ \\
\hline
\end{tabular}

Radiographic spondylosis was determined at the worst (most severe) level among L1/2-L5/S1

Odds ratios were calculated by logistic regression analysis after adjustment for other variables

$B M I$ body mass index, KL Kellgren-Lawrence grading, Stiffness index, stiffness index by quantitative ultrasound at calcaneal bone, OR odds ratio,

$\mathrm{Cl}$ confidence interval

$* p<0.05 ; \dagger p<0.01$

We showed that a higher prevalence of radiographic lumbar spondylosis $(\mathrm{KL} \geq 2)$ was seen at $\mathrm{L} 3 / 4$ and $\mathrm{L} 2 / 3$, and that a higher prevalence of radiographic lumbar spondylosis (KL $\geq 3$ ) was seen at L5/S1 and L4/5. O'Neill et al. [4] reported that osteophytes occurred most frequently at L2/3 in women. Kramer [6] reported that osteophytes and disc space narrowing were most prevalent at L4/5 in women. Teraguchi et al. [14] reported that the prevalence of disc degeneration in the lumbar spine using magnetic resonance imaging (MRI) was highest at L4/5 in women. These differences may be due to differences in ethnicity, the definition of lumbar spondylosis or the assessment method applied (radiograph or MRI).

The association between lumbar spondylosis and low back pain is controversial. Some studies have reported an association [1, 3, 7, 9-11], but others have not $[15,16,19]$. In our study, lumbar spondylosis $(\mathrm{KL} \geq 3)$ at the middle or lower level was associated with low back pain. On the other hand, the majority of subjects with lumbar spondylosis ( $K L \geq 2: 76.7 \%$;
$\mathrm{KL} \geq 3: 38.8 \%)$ did not show low back pain (20.0\%) (Table 2). These findings were somewhat conflicting. Furthermore, no standardized methods have been devised for investigating the relationship between lumbar spondylosis and low back pain; different thresholds have been used, such as worst level $[1,7,10,11,15,17,19]$, number of degenerated discs $[1,3,16,19]$, average level $[9,16,19]$, and single spinal level $[3,7]$. Such differences would inevitably contribute to the variability of findings between studies.

This study has several limitations that must be considered. First, since this study used a cross-sectional design, our results do not necessarily show a causal relationship. Second, data on spinal canal stenosis, degeneration at facet joints, or other spinal disorders or psychological distress causing low back pain were not available in our study. Third, we did not collect data on pain severity. Further study is needed to clarify the severity of low back pain using a visual analogue or numeric pain rating scale to assess the relationship between severity of

Table 5 Association of Kellgren-Lawrence $(K L)$ grade $(K L=2, K L \geq 2$ and $K L \geq 3$ relative to $K L<2$, and $K L \geq 3$ relative to $K L<3)$ at each intervertebral level with low back pain

\begin{tabular}{|c|c|c|c|c|c|c|}
\hline & & $\mathrm{L} 1 / 2$ & $L 2 / 3$ & $L 3 / 4$ & $L 4 / 5$ & $L 5 / S 1$ \\
\hline & reference & $\begin{array}{l}\text { OR } \\
(95 \% \mathrm{Cl})\end{array}$ & $\begin{array}{l}\text { OR } \\
(95 \% \mathrm{Cl})\end{array}$ & $\begin{array}{l}\text { OR } \\
(95 \% \mathrm{Cl})\end{array}$ & $\begin{array}{l}\text { OR } \\
(95 \% \mathrm{Cl})\end{array}$ & $\begin{array}{l}\text { OR } \\
(95 \% \mathrm{Cl})\end{array}$ \\
\hline \multirow[t]{2}{*}{$\mathrm{KL}=2$} & $\mathrm{KL}<2$ & 1.16 & 0.87 & 0.90 & 1.19 & 1.55 \\
\hline & & $(0.66-2.02)$ & $(0.52-1.45)$ & $(0.55-1.48)$ & $(0.68-2.05)$ & $(0.82-2.91)$ \\
\hline \multirow[t]{2}{*}{$K L \geq 2$} & $\mathrm{KL}<2$ & 1.31 & 1.03 & 1.07 & 1.57 & $1.77^{*}$ \\
\hline & & $(0.80-2.15)$ & $(0.64-1.65)$ & $(0.67-1.70)$ & $(0.99-2.50)$ & $(1.09-2.86)$ \\
\hline \multirow[t]{2}{*}{$K L \geq 3$} & $\mathrm{KL}<2$ & 1.93 & 1.91 & $2.57^{*}$ & $2.49^{*}$ & $1.88^{*}$ \\
\hline & & $(0.93-3.99)$ & $(0.92-3.97)$ & $(1.19-5.55)$ & $(1.35-4.56)$ & $(1.06-3.35)$ \\
\hline \multirow[t]{2}{*}{$K L \geq 3$} & $\mathrm{KL}<3$ & 1.66 & 1.86 & $2.54^{*}$ & $2.19^{*}$ & $1.76^{*}$ \\
\hline & & $(0.84-3.28)$ & $(0.96-3.62)$ & $(1.26-5.14)$ & $(1.25-3.84)$ & $(1.02-3.03)$ \\
\hline
\end{tabular}

Odds ratios were calculated by logistic regression analysis compared with subjects with KL grade 0 or 1 after adjustment for age, body mass index, and stiffness index at calcaneal bone

$O R$ odds ratio, $\mathrm{Cl}$ confidence interval

${ }^{*} p<0.05$ 
degenerative changes and severity of low back pain. The KL grade does not discriminate according to the degree of disc space narrowing. Caution is thus needed when interpreting the results. Fourth, a relatively high proportion of women (13.4\%: 77/573) was excluded from analysis because of the poor technical quality of radiographs, which may have led to selection bias. Fifth, because this study only included women, our findings may not be generalizable to men.

\section{Conclusions}

Lumbar spondylosis (KL $\geq 3$ ) at L3/4, L4/5 or L5/S1 was associated with low back pain among communitydwelling Japanese women. Severe lumbar spondylosis at the middle or lower level may contribute to low back pain.

\section{Abbreviations}

BMD: Bone mineral density; BMI: Body mass index; Cls: Confidence intervals; DEXA: Dual-energy X-ray absorptiometry; KL: Kellgren-Lawrence; MRI: Magnetic resonance imaging; ORs: Odds ratios; QUS: Quantitative ultrasound

\section{Acknowledgements}

None.

\section{Funding}

This study was supported in part by the Japan Society for the

Promotion of Science.

\section{Availability of data and materials}

The data supporting our findings are provided within this manuscript.

\section{Authors' contributions}

RT, YA, KA, TN, SM, NT and KA participated in the design of the study, performed the statistical analysis and drafted the manuscript. YA, MT, AY, $\mathrm{TM}, \mathrm{SM}, \mathrm{KA}$ and $\mathrm{MO}$ conceived of the study and participated in the acquisition of data. KA and $\mathrm{MO}$ participated in the whole design and coordination of the study, performed the statistical analysis and helped to draft the manuscript. All authors read and approved the final manuscript.

\section{Competing interests}

The authors declare that they have no competing interests.

\section{Consent for publication}

Not applicable.

\section{Ethics approval and consent to participants}

This study was approved by the Ohshima local ethics committee. All subjects gave written informed consent before enrolling.

\section{Author details}

'Department of Orthopaedic Surgery, Nagasaki University Graduate School of Biomedical Sciences, 1-7-1 Sakamoto, Nagasaki 852-8501, Japan. 2Department of Public Health, Nagasaki University Graduate School of Biomedical Sciences, 1-12-4 Sakamoto, Nagasaki 852-8523, Japan.

Received: 17 May 2016 Accepted: 18 November 2016

Published online: 01 December 2016

\section{References}

1. Lawrence JS. Disc degeneration. Its frequency and relationship to symptoms. Ann Rheum Dis. 1969;28:121-38.

2. van Saase JL, van Romunde LK, Cats A, Vandenbroucke JP, Valkenburg HA. Epidemiology of osteoarthritis: Zoetermeer survey. Comparison of radiological osteoarthritis in a Dutch population with that in 10 other populations. Ann Rheum Dis. 1989;48:271-80.

3. Symmons DP, van Hemert AM, Vandenbroucke JP, Valkenburg HA. A longitudinal study of back pain and radiological changes in the lumbar spines of middle aged women. II. Radiographic findings. Ann Rheum Dis. 1991:50:162-6.

4. O'Neill TW, McCloskey EV, Kanis JA, Bhalla AK, Reeve J, Reid DM, Todd C, Woolf AD, Silman AJ. The distribution, determinants, and clinical correlates of vertebral osteophytosis: a population based survey. J Rheumatol. 1999;6: 842-8.

5. Hassett G, Hart DJ, Manek NJ, Doyle DV, Spector TD. Risk factors for progression of lumbar spine disc degeneration: the Chingford Study. Arthritis Rheum. 2003:48:3112-7.

6. Kramer PA. Prevalence and distribution of spinal osteoarthritis in women. Spine. 2006:31(24):2843-8.

7. Muraki S, Oka H, Akune T, Mabuchi A, En-Yo Y, Yoshida M, Saika A, Suzuki T, Yoshida H, Ishibashi H, Yamamoto S, Nakamura K, Kawaguchi H, Yoshimura $\mathrm{N}$. Prevalence of radiographic lumbar spondylosis and its association with low back pain in elderly subjects of population-based cohorts: the ROAD study. Ann Rheum Dis. 2009;68:1401-6.

8. Brinjikji W, Luetmer PH, Comstock B, Bresnahan BW, Chen LE, Deyo RA, Halabi S, Turner JA, Avins AL, James K, Wald JT, Kallmes DF, Jarvik JG. Systematic literature review of imaging features of spinal degeneration in asymptomatic populations. Am J Neuroradiol. 2015;36:811-6.

9. Cheung KM, Karppinen J, Chan D, Ho DW, Song YQ, Sham P, Cheah KS, Leong JC, Luk KD. Prevalence and pattern of lumbar magnetic resonance imaging changes in a population study of one thousand forty-three individuals. Spine. 2009:34:934-40.

10. Chaiwanichsiri D, Jiamworakul A, Jitapunkul S. Lumbar disc degeneration in Thai elderly: a population-based study. J Med Assoc Thai. 2007:90:2477-81.

11. Hancock M, Maher C, Macaskill P, Latimer J, Kos W, Pik J. MRI findings are more common in selected patients with acute lowback pain than controls? Eur Spine J. 2012;21:240-6.

12. Kellgren $\mathrm{JH}$, Lawrence JS. Osteo-arthrosis and disk degeneration in an urban population. Ann Rheum Dis. 1958;17:388-97.

13. Yoshimura N, Dennison E, Wilman C, Hashimoto T, Cooper C. Epidemiology of chronic disc degeneration and osteoarthritis of the lumbar spine in Britain and Japan: a comparative study. J Rheumatol. 2000;27:429-33.

14. Teraguchi M, Yoshimura N, Hashizume H, Muraki S, Yamada H, Minamide A, Oka H, Ishimoto Y, Nagata K, Kagotani R, Takiguchi N, Akune T, Kawaguchi $H$, Nakamura K, Yoshida M. Prevalence and distribution of intervertebral disc degeneration over the entire spine in a population-based cohort: the Wakayama Spine Study. Osteoarthritis Cartilage. 2014;22:104-10.

15. Horikawa K, Kasai Y, Yamakawa T, Sudo A, Uchida A. Prevalence of osteoarthritis, osteoporotic vertebral fractures, and spondylolisthesis among the elderly in a Japanese village. J Orthop Surg. 2014;14:9-12.

16. Witt I, Vestergaard A, Rosenklint A. A comparative analysis of x-ray findings of the lumbar spine in patients with and without lumbar pain. Spine. 1984; 9:298-300.

17. van Saase $J$, Vandenbroucke JP, van Romunde LK, Valkenburg HA. Osteoarthritis and obesity in the general population. A relationship calling for an explanation. J Rheumatol. 1988:15:1152-8.

18. Mariconda M, Lotti G, Fava R, Midolo R, Longo C, Milano C. Quantitative ultrasound measurements of the calcaneus in the prediction of lumbar spine degeneration. Eur Spine J. 2004;13:346-53.

19. Steffens D, Hancock MJ, Maher CG, Williams C, Jensen TS, Latimer L. Does magnetic resonance imaging predict future low back pain? A systematic review. Eur J Pain. 2014;18:755-65.

20. Kinoshita H, Tamaki T, Hashimoto T, Kasagi F. Factors influencing lumbar spine bone mineral density assessment by dual-energy $\mathrm{X}$-ray absorptiometry: comparison with lumbar spinal radiogram. J Orthop Sci. 1998;3:3-9.

21. Miyakoshi N, Itoi E, Murai H, Wakabayashi I, Ito H, Minato T. Inverse relation between osteoporosis and spondylosis in postmenopausal women as evaluated by bone mineral density and semiquantitative scoring of spinal degeneration. Spine. 2003;28:492-5.

22. Harada A, Okuizumi H, Miyagi N, Genda E. Correlation between bone mineral density and intervertebral disc degeneration. Spine. 1998;23:857-61.

23. Hans D, Schott AM, Chapuy MC, Benamar M, Kotzki PD, Cormier C, Pouilles $J M$, Meunier PJ. Ultrasound measurements on the os calcis in a prospective multicenter study. Calcif Tissue Int. 1994;55:94-9.

24. Kellgren JH, Lawrence JS. The epidemiology of chronic rheumatism: atlas of standard radiographs of arthritis. Oxford: Black Scientific; 1963. 